\title{
Habitat selection and diet in two species of pipefish from seagrass: sex differences
}

\author{
A. S. Steffe ${ }^{1}$, M. Westoby ${ }^{1}$, J. D. Bell ${ }^{1,2}$ \\ ${ }^{1}$ School of Biological Sciences, Macquarie University, North Ryde, NSW 2109, Australia \\ ${ }^{2}$ Fisheries Research Institute, PO Box 21, Cronulla, NSW 2230, Australia
}

\begin{abstract}
Pipefishes Stigmatopora argus and S. nigra were collected during field experiments to test responses of seagrass-associated fishes to changes in the height and density of seagrass leaves. Most pipefish greatly preferred long, high-density seagrass leaves to short or low-density leaves. The exception was female $S$. argus, which were found in thinned long seagrass as often as in dense long. Females of both species had fuller guts than males irrespective of habitat, consistent with the idea that males suffer some loss of feeding efficiency due to adaptations for brooding young. Sex ratios measured at 2 different spatial scales were biased in favour of males for both species. For both species the clutch size of male pipefish with completely filled broodpouches was, on average, the same as the number of developing ovarian eggs in females. These results are reviewed in light of current sexual selection theory.
\end{abstract}

\section{INTRODUCTION}

The family Syngnathidae - pipefishes and seahorses - is characterized by extensive male parental investment in the rearing of young. In many species, males carry the eggs and sometimes newly hatched young in a broodpouch, located on the ventral surface just behind the vent (see Breder \& Rosen 1966 for a general review). The unusual reproductive biology of this group has been the subject of many popular articles but there is little detailed ecological information about them (Gronell 1984, Howard \& Koehn 1985). This is surprising given that syngnathids form a large component of fish communities associated with seagrasses (Pollard 1984).

Sexual selection theory predicts that the sex making the biggest investment in supporting offspring will be a limiting resource for the other sex. Ordinarily females are the limiting resource for males. The sex which does not invest as much (ordinarily males) will compete more intensively for reproductive success. This sex is likely to have more development of secondary sexual characters, more elaborate sexual display, and greater variance of lifetime reproductive success. The 'highrisk high-reward' situation in which members of this sex find themselves may lead to lower survivorship and a correspondingly biased operational sex ratio.
Because syngnathid males invest heavily in offspring relative to males of other taxa, it is possible that they rather than females are the sex in limited supply. To the extent that this is true, sexual selection theory would predict that female rather than male syngnathids will have the various features listed above as typically male characteristics, and the syngnathids have been pointed out as interesting and important test cases for sexual selection theory (Trivers 1972, 1985, Williams 1975). However, little quantitative evidence has so far been reported as to relevant aspects of the field biology of syngnathids.

Various kinds of evidence are relevant to assessing the syngnathids as tests of sexual selection theory. First, there is observational evidence as to kinds and degrees of sexual dimorphism (Breder \& Rosen 1966), reproductive behaviour (Gudger 1905, Fiedler 1954, Gronell 1984, Berglund et al. 1988) and sex ratios (Strawn 1958, Bayer 1980, Gronell 1984). Second, there is evidence as to the actual magnitude of investment by males relative to females. Only Berglund et al. (1986) have attempted to measure investment on a physiological basis. They found some evidence for direct energy transfer from males to offspring but concluded direct energy investment by males was not greater than by females. Many technical difficulties lie in the way of improving these measurements. Further, physiological 
evidence does not settle the question of relative cost of reproduction, because no data exist as to losses in agility due to the male broodpouch, with possible costs in higher predation or less efficient feeding.

Here we contribute a third kind of evidence, on whether habitat selection by the sexes is different under field experimental conditions. The sexes might be expected to show differences in habitat selection because of sexual display behaviour, or because differences in colouration and agility lead to differences in feeding tactics or predation hazard. Our evidence arose initially as a by-product of 2 field experiments in which the height and density of seagrass leaves were manipulated to study responses of all fish species (Bell \& Westoby 1986a). Two pipefish species were abundant in these experiments, and effects on overall numbers have already been reported. Density responses to manipulated seagrass were behavioural and short-term rather than due to differential mortality (Bell \& Westoby 1986a). Stigmatopora argus was the predominant pipefish in Posidonia australis beds in Botany Bay, Australia, whilst S. nigra was most abundant in Zostera capricorni habitats (Bell \& Westoby 1986a). Here we report data with the sexes analysed separately. In addition we present data on sex ratios from these and other populations in different seagrass beds (Bell \& Westoby 1986b). We measured gut contents to assess the hypothesis that there are differences between sexes or between habitats in feeding success, or interactions, whereby the best habitat for feeding is different depending on sex.

We do not present the evidence reported here as a complete test of sexual selection theory in these syngnathids. However we believe it represents a useful increase in knowledge of relevant aspects of biology in these organisms, which can be used to test some predictions made by the theory.

\section{METHODS}

Source of data. Data presented in this paper were derived from specimens of Stigmatopora argus and S. nigra collected during the field experiments of Bell \& Westoby (1986a). These experiments were designed to assess whether changes in leaf height and density of seagrass evoked changes in the abundance of associated fishes. A brief summary of the experiments is set out below.

Seagrass manipulation experiments. Stigmatopora argus were collected from 4 Posidonia australis stations during April-May 1983, and S. nigra from 5 Zostera capricorni stations during October-November 1982, all in Botany Bay $\left(34^{\circ} 1^{\prime} \mathrm{S}, 151^{\circ} 11^{\prime} \mathrm{E}\right)$ on the east coast of Australia.
For both Posidonia and Zostera, each station was a block of 4 contiguous treatments, with each treatment consisting of a $6 \times 6 \mathrm{~m}$ plot of seagrass. Seagrass treatments were (1) dense long (untreated) leaves; (2) long leaves thinned to $30 \%$ untreated density; (3) dense leaves cut to $30 \%$ untreated height $t_{i}$ and (4) leaves cut and thinned to $30 \%$ untreated height and density. Treatment positions were randomised for each station. The manipulated level of treatments approximated lowest natural leaf density and height of Zostera and Posidonia in Botany Bay (Bell \& Westoby 1986a).

Fishes were collected using fine meshed nets and rotenone poison. Detailed descriptions of the sampling stations, preparation of seagrass treatments, collection of fauna, and the statistical implications of the experimental design are given in Bell \& Westoby (1986a).

Bell \& Westoby (1986a) did not sex pipefish but analyzed the data for responses of total abundances to treatments. Here we are concerned with whether adult males and females responded differently within each pipefish species. After testing for homogeneity of variance we used a 4-way randomized complete block design ANOVA (Sokal \& Rohlf 1969) with height, density, and sex being fixed factors, and with blocks (=stations) being a random factor. All significant interactions were decomposed using the Student-Newman-Keuls (SNK) a posteriori comparison of means.

Sexing pipefish. Although both species are sexually dimorphic it was often difficult to distinguish small females from juvenile fish. Thus, we decided to classify as juveniles all fishes smaller than the minimum length at which a male broodpouch was present (minimum male total length). All fishes larger than the minimum male total length were classified as adults. Males were easily recognized by the presence of a ventral broodpouch on the tail. All other fishes were classified as females even if they did not possess any of the female secondary sexual characters. Thus it is possible that we overestimated the proportion of adult females in the reproductive population. A few damaged fish which could not be measured, or sexed accurately using sexually dimorphic characters, were excluded from the analysis

Size distribution and sex ratio. We measured the total lengths (TL) of all pipefish whose tails had not been broken during preservation to (1) examine the size distribution of the sampled populations, and (2) calculate the minimum male total length for accurate sexing of small adult pipefish.

We obtained sex ratios for Stigmatopora argus and $S$. nigra from 2 sources: (1) the seagrass manipulation experiments reported here; and (2) a comparative study based on collections from natural Posidonia and Zostera seagrass beds of varying height and density throughout Botany Bay (Bell \& Westoby 1986b). The 
Posidonia collections of $S$. argus were made during May 1983 whilst the Zostera collections of S. nigra were made during December 1982.

Dietary analyses. The diets of Stigmatopora argus and $S$. nigra were examined to determine whether the observed responses of male and female pipefish to changes in seagrass leaf height and density were associated with differences in feeding.

For each species, we initially examined the gut contents of 40 fish (20 males and 20 females) selected at random from all seagrass habitat treatments. Subsequently, for each species we examined gut fullness and the size of prey eaten. Gut fullness analyses for both species are based on 10 fish of each sex, from each of dense long and thinned long treatments. Short seagrass was little used by the fish, and we were interested principally in understanding the choice made between dense long versus thinned long seagrass by the sexes (see 'Results'). In the case of $S$. argus we dried the contents of the long, tubular gut at $80^{\circ} \mathrm{C}$ overnight and obtained dry weights ( $\pm 1.0 \mathrm{mg}$ ). This technique could not be applied accurately to Stigmatopora nigra because they were much smaller. Instead we counted the total number of prey organisms present in the gut.

We examined the size of prey items eaten by estimating the volume of 5 randomly selected prey items per gut. The maximum width and length of the food items were measured to the nearest $0.05 \mathrm{~mm}$ and volume was calculated by the equation for a prolate spheroid, $\mathrm{V}=$ $4 / 3 \pi a \cdot b^{2}$, where $a$ is half the maximum length and $b$ is half the maximum width. We used the mean volume of food items per gut for the analyses. For Stigmatopora argus analysis is based on 10 fish of each sex from each of dense long and thinned long treatments whilst for $S$. nigra we examined 5 fish of each sex taken from the same treatments.

The gut fullness and prey size data were tested for homogeneity of variance and when necessary were transformed logarithmically. In the case of Stigmatopora nigra the data from both analyses remained heteroscedastic after transformation. For this species we performed the analyses using transformed data and set our critical level at $p<0.01$ to compensate for the likelihood of a Type 1 error (Underwood 1981).

The experimental design of the dietary analyses was orthogonal. The data for each species were subjected to a 2-way analysis of variance with habitat type and sex being fixed factors.

Determination of male clutch size and number of developing ovarian eggs. Most of the pipefish used in the dietary studies were also examined for reproductive information. Male clutch size, i.e. the number of eggs in the male broodpouch, was determined by removing the egg mass from the broodpouch and counting the individual eggs. As Stigmatopora argus and $S$. nigra deposit their eggs into membranous egg compartments within the broodpouch we discarded all fish in which the middle portion of the pouch was empty but had egg compartments. In these instances we regarded loss of eggs as an artifact of preservation and handling.

We dissected females and examined their strap-like ovaries for evidence of egg development. In both species, egg development could be quantified easily by counting the number of large oocytes (here termed 'developing eggs') present. The developing eggs were quite large and clearly visible under low magnification, usually being aligned within the ovaries in single file.

\section{RESULTS}

\section{Seagrass manipulation experiments}

Stigmatopora argus exhibited significant sex differences in habitat selection between dense and thinned treatments in long Posidonia (HDS and DS interactions in Table 1). The abundance of females in dense long and thinned long seagrass was about equal, but males were concentrated in dense long seagrass (Fig. 1a, b). $S$. argus was more abundant in long than in short seagrass irrespective of leaf density (Fig. 1a).

Table 1. Stigmatopora spp. 4-way randomized complete block design ANOVA (height $\times$ density $\times$ sex $\times$ block) tables for abundances of $S$. argus in Posidonia and S. nigra in Zostera (raw data)

\begin{tabular}{|c|c|c|c|c|}
\hline Source & SS & $\mathrm{df}$ & MS & $\mathrm{f}$ \\
\hline \multicolumn{5}{|c|}{ S. argus in Posidonia } \\
\hline Height & 840.50 & 1 & 840.50 & $53.55 \cdots$ \\
\hline Density & 91.13 & 1 & 91.13 & $5.81^{\circ}$ \\
\hline Sex & 60.50 & 1 & 60.50 & $3.85 \mathrm{NS}$ \\
\hline Block & 101.38 & 3 & 33.79 & $2.15 \mathrm{NS}$ \\
\hline HD & 40.50 & 1 & 40.50 & $2.58 \mathrm{NS}$ \\
\hline HS & 45.13 & 1 & 45.13 & $2.88 \mathrm{NS}$ \\
\hline DS & 162.00 & 1 & 162.00 & $10.32 \cdots$ \\
\hline HDS & 105.13 & 1 & 105.13 & $6.70^{\circ}$ \\
\hline Error & 329.63 & 21 & 15.70 & \\
\hline \multicolumn{5}{|c|}{ S. nigra in Zostera } \\
\hline Height & 184.90 & 1 & 184.90 & $23.27 \cdots$ \\
\hline Density & 8.10 & 1 & 8.10 & $1.02 \mathrm{NS}$ \\
\hline Sex & 44.10 & 1 & 44.10 & $5.55^{\circ}$ \\
\hline Block & 262.75 & 4 & 65.69 & $8.27 \cdots$ \\
\hline HD & 72.90 & 1 & 72.90 & $9.18^{\cdots}$ \\
\hline HS & 22.50 & 1 & 22.50 & $2.83 \mathrm{NS}$ \\
\hline DS & 4.90 & 1 & 4.90 & $0.62 \mathrm{NS}$ \\
\hline HDS & 4.90 & 1 & 4.90 & $0.62 \mathrm{NS}$ \\
\hline Error & 222.45 & 28 & 7.94 & \\
\hline \multicolumn{5}{|c|}{$\begin{array}{l}\cdot 0.05>p>0.01 ; \cdots 0.01>p>0.001 ; \cdots p<0.001 \\
\text { NS: not significant }\end{array}$} \\
\hline
\end{tabular}



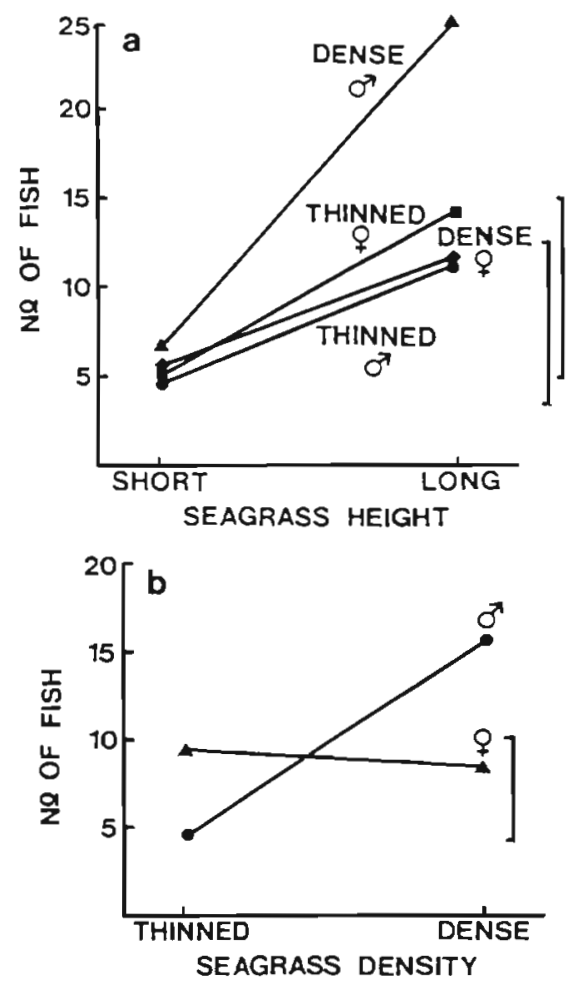

Fig. 1. Stigmatopora argus. (a) Comparison of treatment means from the height $x$ density $x$ sex 3 -way ANOVA. (b) Comparison of mean abundance of males and females in thinned and dense Posidonia (long and short treatments combined). Brackets denote means that are not significantly different $(p<0.05)$ by SNK test

Sexes of Stigmatopora nigra did not differ in habitat selection; there were no significant interactions involving sex (Table 1). The significant HD interaction (Table 1) reflects the higher abundances of $S$. nigra in dense seagrass when Zostera is long, but no significant difference in short Zostera where abundances were low
(Fig. 2). Like its congener, $S$. nigra was abundant in long seagrass, with both sexes having significantly lower abundances in short Zostera (Table 1, Fig. 2).

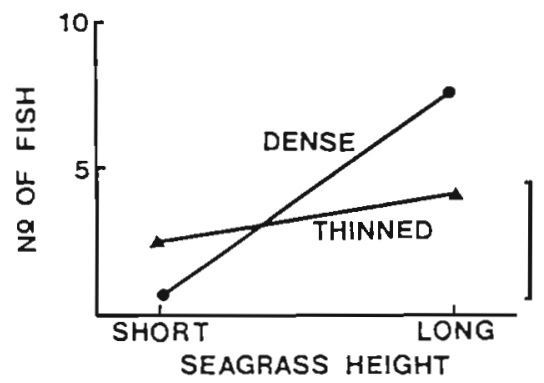

Fig. 2. Stigmatopora nigra. Comparison of mean abundances (sexes combined) from 4 Zostera treatments. Bracket denotes means that are not significantly different $(p<0.05)$ by SNK test.

\section{Size distributions and sex ratios}

Minimum male total lengths of Stigmatopora argus and $S$. nigra were $125 \mathrm{~mm}$ and $65 \mathrm{~mm}$, respectively (Fig. 3a, b). For both species, the sex ratios were biased in favour of males (Table 2). Similarly, sex ratios obtained from fishes collected from a wide range of seagrass sampling stations throughout the Bay (Bell \& Westoby 1986b) were biased in favour of males, and these results were consistent with those obtained from the seagrass manipulation experiments (Table 2 ).

\section{Diet and feeding comparisons}

Both species preyed predominantly on copepods. Other dietary components were minor (Table3). As both species were significantly more abundant in long

Table 2. Stigmatopora spp. Total abundances of $S$. argus from Posidonia and S. nigra from Zostera, percentage of females and their $95 \%$ confidence limits for the seagrass manipulation experiments, and for collections at many other seagrass stations throughout the bay (pooled)

\begin{tabular}{|c|c|c|c|}
\hline Source of fish & Total & $\%$ Female & $\begin{array}{l}95 \% \text { confidence limits } \\
\text { for } \% \text { females }\end{array}$ \\
\hline $\begin{array}{l}\text { S. argus } \\
\text { Posidonia } \\
\text { Manipulation experiment }\end{array}$ & 334 & 43 & $37-49$ \\
\hline $\begin{array}{l}\text { Posidonia } \\
\text { Seagrass stations throughout Bay }\end{array}$ & 351 & 42 & $36-48$ \\
\hline $\begin{array}{l}\text { S. nigra } \\
\text { Zostera } \\
\text { Manipulation experiment }\end{array}$ & 150 & 36 & $28-45$ \\
\hline $\begin{array}{l}\text { Zostera } \\
\text { Seagrass stations throughout Bay }\end{array}$ & 141 & 38 & $30-47$ \\
\hline
\end{tabular}



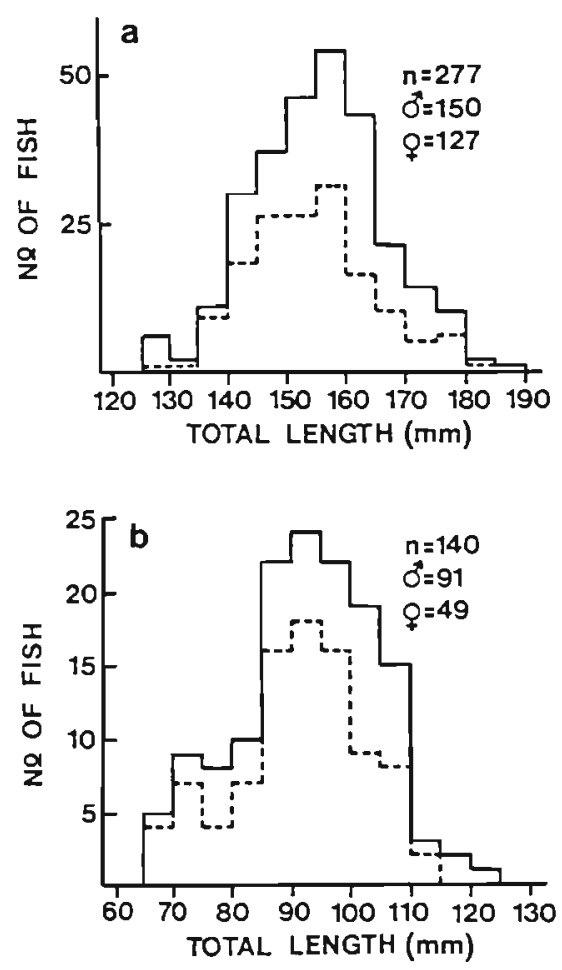

Fig. 3. (a) Stigmatopora argus. Length frequency histogram of adults from the Posidonia manipulation experiment. (b) Stigmatopora nigra. Length frequency histogram of adults from the Zostera manipulation experiment. Dashed lines represent males; unbroken lines represent total reproductive population. Pipefish which could not be measured accurately are not included

seagrass we restricted the comparative dietary studies to fishes of about equal size collected from this favoured habitat (Stigmatopora argus: $n=20$ males, $\overline{\mathrm{x}}=155.4 \mathrm{~mm}$ TL, $\mathrm{SD}=11.2 ; n=20$ females, $\overline{\mathrm{x}}=$ $158.4 \mathrm{~mm}$ TL, $\mathrm{SD}=10.7$; S. nigra: $n=20$ males, $\overline{\mathrm{x}}=$ $94.2 \mathrm{~mm} \mathrm{TL}, \mathrm{SD}=9.0 ; n=20$ females, $\overline{\mathrm{x}}=92.1, \mathrm{SD}=$
Table 3. Stigmatopora spp. Percentage volume of food items eaten by $S$. argus in Posidonia and S. nigra in Zostera

\begin{tabular}{|lcc|}
\hline Food item & $\begin{array}{c}\text { S. argus } \\
\% \text { Volume } \\
(n=40)\end{array}$ & $\begin{array}{c}\text { S. nigra } \\
\% \text { Volume } \\
(n=40)\end{array}$ \\
\hline Copepods & 93.6 & 96.6 \\
Ostracods & 2.8 & - \\
Amphipods & 2.0 & 2.3 \\
Penaid mysis & 0.3 & 0.5 \\
Crab zoea and megalopa & 0.7 & - \\
Isopods & 0.2 & - \\
Branchiopods & 0.1 & 0.5 \\
Bivalves & 0.2 & - \\
Gastropods & 0.1 & 0.1 \\
\end{tabular}

13.4). For both species we found no significant differences in the size of prey eaten by fish in dense long compared to thinned long habitats, and no significant differences in the size of prey ingested between sexes (Tables 4 and 5). Because both species fed mainly on copepods we used prey size as a measure of prey quality. Thus differences in gut fullness were not complicated by prey quality effects. In summary there were no differences in the quality of prey eaten between dense and thinned habitats, nor between sexes for either species.

For both species females had more food in their guts than males (Tables 4 and 5). Dense long Posidonia was found to be a significantly better feeding habitat for Stigmatopora argus than thinned long Posidonia (Table 5). However, S. nigra showed no significant difference in gut fullness between dense long Zostera and thinned long Zostera habitats (Table 5). The interaction terms between habitat type and sex were not significant for either species (Table 5); that is, the tendency of females to have fuller guts was not affected by habitat.

Table 4. Stigmatopora spp. Means and standard deviations of pipefish gut fullness from the 2 favoured seagrass habitat treatments (dense long and thinned long). S. argus are from Posidonia, gut contents are given as dry weight (mg). S. nigra are from Zostera, gut contents are given as total number of food items

\begin{tabular}{|c|c|c|c|c|}
\hline & \multicolumn{2}{|c|}{ Dense long seagrass } & \multicolumn{2}{|c|}{ Thinned long seagrass } \\
\hline & 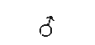 & $q$ & $0^{*}$ & $q$ \\
\hline \multicolumn{5}{|c|}{$S$. argus: dry weight $(\mu \mathrm{g})$} \\
\hline$n$ & 10 & 10 & 10 & 10 \\
\hline$\overline{\mathrm{x}}$ & 3.9 & 4.6 & 1.3 & 1.9 \\
\hline SD & 0.8 & 1.3 & 0.4 & 0.4 \\
\hline \multicolumn{5}{|c|}{ S. nigra: total number of food items } \\
\hline$n$ & 10 & 10 & 10 & 10 \\
\hline$\overline{\mathrm{x}}$ & 137 & 593 & 159 & 393 \\
\hline $\mathrm{SD}$ & 45 & 364 & 68 & 168 \\
\hline
\end{tabular}


Table 5. Stigmatopora spp. F-ratios and significance levels from 2-way ANOVAS for comparisons of gut fullness (as in Table 5) and volumes of individual prey. S. argus in Posidonia and S. nigra in Zostera

\begin{tabular}{|c|c|c|c|c|}
\hline $\begin{array}{l}\text { S. argus in Posidonia } \\
\text { Source }\end{array}$ & $d f$ & $\begin{array}{l}\text { Gut fullness } \\
\log (x+1) \text { data }\end{array}$ & $\mathrm{df}$ & $\begin{array}{l}\text { Prey volume } \\
\text { raw data }\end{array}$ \\
\hline Habitat & 1 & $155.20 \cdots$ & 1 & $0.85 \mathrm{NS}$ \\
\hline Sex & 1 & $8.85 \cdots$ & 1 & $0.26 \mathrm{NS}$ \\
\hline HS & 1 & $0.58 \mathrm{NS}$ & 1 & $1.03 \mathrm{NS}$ \\
\hline Residual & 36 & & 36 & \\
\hline $\begin{array}{l}\text { S. nigra in Zostera } \\
\text { Source }\end{array}$ & $\mathrm{df}$ & $\begin{array}{l}\text { Gut fullness }{ }^{a} \\
\log x \text { data }\end{array}$ & $\mathrm{df}$ & $\begin{array}{l}\text { Prey volume } \\
\text { log } x \text { data }\end{array}$ \\
\hline Habitat & 1 & $0.15 \mathrm{NS}$ & 1 & $4.31 \mathrm{NS}$ \\
\hline Sex & 1 & $35.68 \cdots$ & 1 & $0.87 \mathrm{NS}$ \\
\hline HS & 1 & $1.05 \mathrm{NS}$ & 1 & $3.09 \mathrm{NS}$ \\
\hline Residual & 36 & & 16 & \\
\hline \multicolumn{5}{|c|}{$\because 0.01>p>0.001 ; \cdots p<0.001$} \\
\hline \multirow{2}{*}{\multicolumn{5}{|c|}{ NS: not significant }} \\
\hline & & & & \\
\hline
\end{tabular}

\section{Male clutch size and number of developing ovarian eggs}

The mean male clutch size of pipefish which were utilizing all of their available pouch space approximated the mean number of developing ovarian eggs (Table 6). This was true for both species.

Stigmatopora argus males were often found carrying eggs only in the anterior part of the broodpouch with the posterior part remaining unutilized and lacking egg compartments (Table 6). This condition also occurs rarely in $S$. nigra (A. Steffe pers, obs.) but was not observed in this species during this study.

\section{DISCUSSION}

\section{General background}

The females of both Stigmatopora species are larger and broader than males, heavily spotted in the case of $S$. argus, and consequently more conspicuous than males. This type of sexual dimorphism is common in other syngnathid species (Gudger 1905, Fiedler 1954 Breder \& Rosen 1966). The distinctive colouration and shape of females has been interpreted as adapted for display, possibly to both sexes, and active courtship of males. We have shown here that the males are more

Table 6. Stigmatopora spp. Means and standard deviations for the number of developing ovarian eggs in females, clutch size in male broodpouch, and pipefish total lengths for $S$. argus and $S$. nigra

\begin{tabular}{|c|c|c|c|c|c|c|}
\hline \multirow[b]{2}{*}{ S. arg } & \multirow[t]{2}{*}{$\begin{array}{l}\text { Total length } \\
\quad 9(\mathrm{~mm})\end{array}$} & \multirow[t]{2}{*}{$\begin{array}{l}\text { No. of developing } \\
\text { eggs in ovaries }\end{array}$} & \multicolumn{2}{|c|}{$\begin{array}{l}\text { Total length } \\
\delta(\mathrm{mm})\end{array}$} & \multicolumn{2}{|c|}{$\begin{array}{c}\text { Clutch size } \\
\text { (No. eggs in brood pouch) }\end{array}$} \\
\hline & & & & & & \\
\hline$n$ & 28 & 28 & $9^{a}$ & $5^{b}$ & $9^{41}$ & $5^{b}$ \\
\hline $\bar{x}$ & 157.2 & 19.9 & 144.0 & 144.2 & 20.7 & 7.8 \\
\hline $\mathrm{SD}$ & 12.5 & 3.9 & 15.2 & 8.5 & 8.6 & 0.4 \\
\hline \multicolumn{7}{|c|}{ S. nigra } \\
\hline$n$ & 14 & 14 & 11 & & 11. & \\
\hline$\overline{\mathrm{x}}$ & 103.4 & 60.9 & 88.2 & & 58.5 & \\
\hline $\mathrm{SD}$ & 6.0 & 23.8 & 10.6 & & 14.8 & \\
\hline
\end{tabular}


numerous than females in the reproductive population of 2 Stigmatopora species (Table 3). This is consistent with higher female mortalities at some stage of the life history but we cannot eliminate alternative explanations such as biased sex ratios at birth or a greater proportion of females occupying different habitats other than seagrasses.

\section{Habitat selection}

Both sexes of both Stigmatopora species strongly preferred long seagrass to short (Table 1; Figs. 1 a and 2 ). This was not surprising since pipefish are most cryptic when vertically orientated against seagrass leaves (Howard \& Koehn 1985, A. S. pers. obs.).

Males of Stigmatopora argus and both sexes of $S$. nigra strongly preferred dense to thinned seagrass habitats. S. argus collected from dense seagrass habitats were associated with better gut fullness. Possibly dense Posidonia offers better cover to $S$. argus from predators and allows more time for feeding. We expected $S$. nigra in Zostera to feed more successfully in dense seagrass, as $S$. argus did in Posidonia. However, no habitat difference in feeding success was detected for either sex of $S$, nigra. Perhaps the dietary requirements of $S$. nigra, a much smaller species, may be equally met in either thinned or dense Zostera but they prefer the better refuge that dense Zostera habitats provide.

Females of Stigmatopora argus showed a different habitat preference. They were found in thinned long seagrass about as often as in dense long seagrass. Logically, 3 hypotheses might have accounted for this:

(1) They might be able to feed better in thinned seagrass. We falsified this hypothesis by showing female Stigmatopora argus actually fed better in dense seagrass (Tables 4 and 5).

(2) Female Stigmatopora argus might enter thinned seagrass to engage in sexual display towards males or aggressive display towards each other. Their spotted and more ornate colouration, and wider body, suggest a display operating best where visibility is good. One problem with this second hypothesis is that we would expect it to apply to female S. nigra as well. However, female $S$. nigra have the same strong preference for dense seagrass as males. We have 2 hypotheses which could explain this difference between the 2 species. One possibility is that the narrower leaves of Zostera have different effects from broader Posidonia leaves, either in allowing pipefish to see each other, or in allowing predators to see them. It may be relevant that female $S$. nigra do not have the conspicuous colour pattern seen in female $S$. argus, but only the broadening of the body. An alternative possibility is that the differences between species reflect seasonal differences. That is, due to our sampling constraints we collected $S$. argus in late autumn and $S$. nigra in early summer

(3) Some females may be excluded from favoured habitats by intrasexual competition. Females could prefer dense long seagrass but resident females occupying favoured habitats exclude other females from their immediate vicinity. This hypothesis predicts that at low female densities all females would be able to occupy favoured habitats but at high densities some females are forced to occupy less favourable sites. Thus, Stigmatopora nigra females $(\overline{\mathrm{x}}=2.7$ per $6 \times 6 \mathrm{~m}$ treatment plot) were all able to occupy favoured sites whilst the higher densities of $S$. argus females $(\bar{x}=9.1$ per $6 \times 6 \mathrm{~m}$ treatment plot) resulted in many females being displaced to adjacent less favourable habitat.

Hypotheses 2 and 3, with which our data are consistent, both imply that habitat choice in females is shaped by sexual selection.

\section{Males as a limiting resource}

Are males a limiting resource, with females competing to deposit eggs in a supply of broodpouch space which cannot accept all the available eggs? In Stigmatopora there are more reproductive males than females and we have found that single batches of eggs produced by females correspond to the broodpouch space provided by each male (Table 6). Therefore if males are to be a limiting resource, females must be able to produce new batches of eggs faster than males are able to raise a batch to independence.

A close match between broodpouch capacity and the number of eggs produced in one batch by females has been found in the pipefishes Entelurus aequoreus (Guitel 1908 - cited in Breder \& Rosen 1966), Syngnathus schlegeli (Takai \& Mizokami 1959), Syngnathus dumerilii (Huot 1902 - cited in Gudger 1905), Corythoichthys spp. (Gronell 1984) and in the seahorse Hippocampus zosterae (Strawn 1958). Observations of this type suggest that only one female's eggs can be accommodated by a male at any given time (Williams 1975).

A curious observation was that Stigmatopora argus males were often found carrying eggs only in the anterior part of the pouch (Table 6). The remaining unutilized pouch space lacked egg-holding compartments. This condition was rare in S. nigra (A. S. pers. obs.). We have 2 possible explanations for these observations: (1) that for as yet unknown reasons the acceptance of a full-sized clutch has become undesirable for some males; or (2) that a full-sized clutch is the result of polygamous spawning, that is, a male carries some 
eggs from each of several females at any given time. We believe the first hypothesis to be more plausible for 3 reasons. Firstly, polygamy does not account for the close correlation between whole clutch size and the number of developing ovarian eggs. Secondly, total egg compartment number is believed to be determined by the male. Finally, egg transfer and fertilization occur via the anterior end of the pouch so no other eggs can be deposited successfully into the remaining pouch space whilst eggs are carried in the front of the pouch. Thus, our data suggest that $S$. argus and $S$. nigra are sequential polyandrous spawners.

Population structure and spawning habits appear to be quite variable within the Syngnathidae. For example, female-biased sex ratios (Strawn 1958, Bayer 1980), equal sex ratios (Gronell 1984), and male biased sex ratios (this study) have been reported. Similarly, both polygamous (Gudger 1905, Fiedler 1954, Berglund et al. 1988) and monogamous (Gronell 1984) spawning have been documented. This variability in population structure and spawning habits may be partly due to differing degrees of sex role reversal between species.

\section{Cost of male investment in offspring}

Since the direct physiological cost of egg production falls on females, in what sense might males be regarded as making a heavy investment? It may be that their agility is reduced by the broodpouch or by the load of offspring thus limiting their ability to swim, forage and avoid predators (Gronell 1984).

We found that males of both Stigmatopora species consistently had lower gut fullness levels than females, irrespective of habitat. These observed differences in feeding success could not be explained by the sexes eating different size prey or themselves being different sizes. Our data are consistent with the hypothesis that males have measurably decreased foraging capabilities and that this is a partial expression of the total penalty incurred by brooding males. An alternative explanation could be that males do not require as much food as females due to lower energy commitments.

In both Stigmatopora species a male must also bear the cost of making membranous egg-holding compartments within the broodpouch. As these specialized structures are not present in non-brooding males (A. S. pers. obs.) this cost probably recurs for every litter a male broods. Recently males have been shown to provide nutriment to the developing zygotes through these egg-holding compartments (Berglund et al. 1986). Thus, the cost to males of reproduction appears to be considerable.

This article was presented by Dr A. J. Underwood, Sydney. Australia
Acknowledgements. We thank David Haig, Rick Shine, Ann Thresher and Ron Thresher for their constructive comments and suggestions which improved the manuscript. We also thank Rita Steffe for preparing the figures.

\section{LITERATURE CITED}

Bayer, R. D. (1980). Size, seasonality, and sex ratios of the bay pipefish (Syngnathus leptorhynchus) in Oregon. NW Sci. 54: 161-167

Bell, J. D., Westoby, M. (1986a). Importance of local changes in leaf height and density to fishes and decapods associated with seagrasses. J. exp. mar. Biol. Ecol. 104: 249-274

Bell, J. D., Westoby, M. (1986b). Variation in seagrass height and density over a wide spatial scale: effects on common fish and decapods. J. exp. mar Biol. Ecol. 104: 275-295

Berglund, A., Rosenquist, G., Svensson, I. (1986). Reversed sex roles and parental energy investment in zygotes of two pipefish (Syngnathidae) species. Mar. Ecol. Prog. Ser. 29: 209-215

Berglund, A., Rosenqvist, G., Svensson, I. (1988). Multiple matings and paternal bood care in the pipefish Syngnathus typhle. Oikos 51: 184-188

Breder, C. M., Rosen, D. E. (1966). Modes of reproduction in fishes. Natural History Press, New York

Fiedler, K. (1954). Vergleichende Verhaltensstudien an Seenadeln, Schlangennadeln und Seepferdchen (Syngnathidae). Z. Tierpsychol. 11. 358-416

Gronell, A. M. (1984). Courtship, spawning and social organization of the pipefish, Corythoichthys intestinalis (Pisces: Syngnathidae) with notes on two congeneric species. $Z$. Tierpsychol. 65: 1-24

Gudger, E. W (1905). The breeding habits and the segmentation of the eggs of the pipefish, Siphostoma floridae. Proc. U. S. natn Mus. 29: 447-500

Howard, R. K. Koehn, J. D. (1985). Population dynamics and feeding ecology of pipefish (Syngnathidae) associated with eelgrass beds of Western Port, Victoria. Aust. J. mar. Freshwat. Res. 36: 361-370

Pollard, D. A. (1984). A review of ecological studies on seagrass-fish communities, with particular reference to recent studies in Australia. Aquat. Bot. 18: 3-42

Sokal, R. R., Rohlf, F. J. (1969). Biometry. Freeman, San Francisco

Strawn, K. (1958). Life history of the pigmy seahorse Hippocampus zosterae (Jordan and Gilbert) at Cedar Key, Florida. Copeia 1: 16-22

Takai, T., Mizokami, A. (1959). On the reproduction, eggs, and larvae of the pipefish, Syngnathus schlegeli, Kaup. J. Shimonoseki Coll. Fish. 8: 85-89

Trivers, R. L. (1972). Parental investment and sexual selection. In: Campbell, B (ed.) Sexual selection and the descent of man. Aldine, Chicago, p. 136-179

Trivers, R. L. (1985). Social evolution. Benjamin/Cummings Publ. Co Inc., Menlo Park, California

Underwood, A. J. (1981). Techniques of analysis of variance in experimental marine biology and ecology. Oceanogr. mar Biol. A. Rev. 19: 513-605

Williams, G. C. (1975). Sex and evolution. Princeton Univ Press, Princeton, New Jersey

Manuscript first received: June 10,1988

Revised version accepted: April 11, 1989 